\title{
KẾT QUẢ KHẢO SÁT HÌNH THÁI CẤU TRÚC THÂN VÁCH NGĂN MŨI TẠI BỆNH VIỆN TRƯỜ'NG ĐẠI HỌC Y DƯợC CẦN THO' 2018-2020
}

\section{TÓM TẮT}

Mục tiêu: Khảo sát hình thái, kích thước củacấu trúc thân vách ngăn mũi dựa trên MRI 1.5 Tesla. Đối tượng và phương pháp: Mô tả cắt ngang xác định cấu trúc thân vách ngăn dựa trên MRI 1.5 Tesla có cản quang thì $T 1$ của 64 bệnh nhân tại Bệnh viện Trường Đại học Y Dược Cần Thơ năm 2017-2020. Kết quả: Độ tuổi trung bình trong nghiên cứu là 43.2 217 chiều rộng ghi nhận được là $13.1 \mathrm{~mm}$ (SD 2.1mm), chiều cao là 17.5 mm (SD 3.4 mm). Khoảng cách từ thân vách ngăn đến các mốc giải phẫu khác trong khoang mũi được ghi nhận trong nghiên cứu này như sau: khoảng cách từ lõi đến sàng mũi là $21.2 \mathrm{~mm}(\mathrm{SD}$ $2.1 \mathrm{~mm}$ ), đến mặt trước xoang bướm là $36 \mathrm{~mm}$ (SD $3.5 \mathrm{~mm}$ ) và đến chóp mũi là $40.3 \mathrm{~mm}$ (SD 2.9mm). Kết luận: Khảo sát trên 64 trường hợp cho thấy việc đánh giá cấu trúc thân vách ngăn dựa trên hình ảnh MRI dể dàng thực hiện. Kết quả ghi nhận có sự khác biệt so với nghiền cứu của Dary J. Costa (2010), sự khác biệt này có thể liên quan đến đặc điểm cấu trúc hình thái tháp mũi của người Việt Nam so với các chủng tôc khác.

Tư khóa: Thân vách ngăn, hình thoi, quá phát cuốn mũi

\section{SUMMARY \\ INVESTIGATING THE MORPHOLOGY OF BODY NASAL SEPTUM AT CAN THO \\ UNIVERSITY HOSPITAL FROM 2018 TO 2020}

Objectives: investigate the morphology of body nasal septum on MRI 1.5 tesla at Cantho University Hosptal of Medicine and Pharmacy 2018-2020. Objects and methods: Study designs: crosssectional descriptive method. Results: There are 64 cases (34 males, 30 males) were included in this study. The mean age is $43.2 \pm 17$, the mean width of the body septum $13.1 \mathrm{~mm}$ (SD $2.1 \mathrm{~mm}$ ), and the height is $17.5 \mathrm{~mm}$ (SD $3.4 \mathrm{~mm}$ ). Conclusions: The early report of this study in 64 cases offered a good and easy approach in evaluating the size of the nasal septal body. The result of this study had the differences in comparing those of Dary J, Costa. These differentiation can be explained by the racial characteristics between Vietnamese people (Mongolian race and Causian race)

Keywords: Body septum, fusiform, turbinate hypertrophy

\section{I. ĐẶT VẤN ĐỀ}

\author{
*Trường Đại học Y Dược Cần Thơ \\ Chịu trách nhiệm chính: Nguyễn Triều Việt \\ Email: vietctho@gmail.com \\ Ngày nhận bài: 8/8/2021 \\ Ngày phản biên khoa họ: 5/9/2021 \\ Ngày duyệt bài: 21/9/2021
}

\section{Nguyễn Triều Việt*}

Vùng cấu trúc phồng lên của thân vách ngăn là khu vực dãn rộng ra của phần trước trên cao của vách ngăn. Trong y văn, cấu trúc này được mô tả đầu tiên bởi Morgagni vào năm 1662 $[1,2]$, như là "vùng niêm mạc phình to lên nằm phía trước vách ngăn" trong khi đó Schiefferdecker [1] xem như là mạng lưới mạch máu nằm trên phần trước vách ngăn hay là "cuốn vách ngăn.

Khu vực niêm mạc phồng lên này có thể dễ dàng được xác định trên soi mũi trước thông thường bằng đèn clar, khám nội soi và trên các chẩn đoán hình ảnh như CT scan, MRI. Cấu trúc này có thể thay đổi kích thước khi sử dụng thuốc co mạch xịt vào trong hốc mũi. Chính vì vậy, để có thể xác định xác định chính xác kích thước cấu trúc này cần sử dụng thuốc co mạch với một quy trình thích hợp. Thân vách ngăn có tác động lớn đến sự hình thành các cấu trúc hình thành van mũi trong theo nghiên cứu của Miman (2006)[6], khi cấu trúc phồng to hay thu nhỏ sẽ ảnh hưởng đến sự thông khí qua mũi, nhất là tác động đến diện tích cắt ngang của khu vực van mũi trong. Nhiều tác giả trên thế giới như Costa et al (2010)[1] đánh giá thân vách ngăn qua cấu trúc giải phẩu, chụp MRI, và cả mô học với mục tiêu xác định vai trò sinh lý bệnh học của cấu trúc này đối với sự thông khí qua mũi. Nghiên cứu được thực hiện trên nhũng người không có than phiền bệnh lý mũi xoang được đo kích thước khu vực thân vách ngăn. Một nghiên cứu khác của Setlur (2011) [1] trên 100 trường hợp khảo sát mối liên quan giữa thân vách ngăn và lệch vách ngăn qua hình ảnh CT scan ghi nhận mối liên quan đáng kể giữa vách ngăn vẹo và quá phát thân vách ngăn bên đối diện. Do vậy, các tác giả xem thân vách ngăn như là cuốn vách ngăn, có thể ảnh hưởng đến luồng khí lưu thông qua mũi và do đó có thể gây nghẹt mũi, tương tự như cuốn mũi dưới.

Mặc dù cấu trúc này đã được ghi nhận trong y văn thế giới từ hàng thập niên gần đây $y_{h}$ nhưng các nghiên cứu về cấu trúc này hiện tại vấn chưa được chú ý đến tại Việt Nam bao gồm cả hình thái, đánh giá về chức năng khi cấu trúc này phồng to lên tác động đến sự thông khí qua mũi. Chính vì vậy, chúng tôi tiến hành nghiên cứu này với mục tiêu xác định cấu trúc của thân vách ngăn trên những người đến khám tại Bệnh viện Trường Đại học Y Dược Cần Thơ năm 2018-2020. 


\section{II. ĐỐI TƯợNG VÀ PHƯƠNG PHÁP NGHIÊN CỨU}

Đây là nghiên cứu cắt ngang mô tả, được tiến hành trên 64 trường hợp (34 nam, 30 nữ) đến khám tại phòng khám Tai Mũi Họng, Bệnh viện trường Đại học Y Dược Cần Thơ năm 2017-2020. Những trường hợp được đưa vào nghiên cứu được chụp MRI vì các lý do không liên quan đến bệnh lý mũi xoang, quan trọng nhất là không có than phiền ngẹt mũi. Các hình ảnh ghi nhận được sẽ được phân tích và đo kích thước vùng thân vách ngăn. Hình ảnh $3 \mathrm{D}$ được hỗ trợ trên máy tính sẽ phân tích hình ảnh vách ngăn và thân vách ngăn. Thiết bị MRI sử dụng của hãng Siemens 1.5 tesla, chụp ở tư thế nằmcó sử dụng thuốc cản từ.

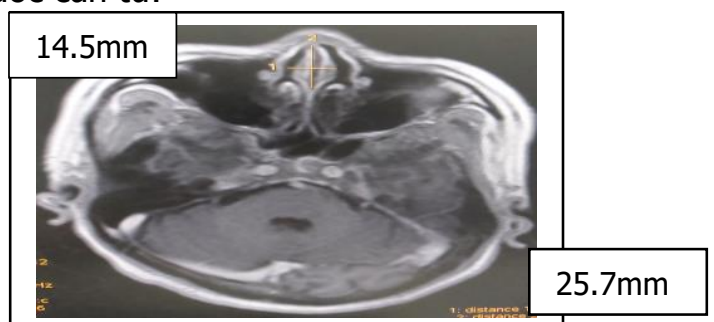

Hình 1. Xác định kích thước thân vách ngăn trên MRI

Cấu trúc thân vách ngăn sẽ được đo trên ba tư thế axial, coronal, và sagittal. Các kích thước được xác định bao gồm chiêu cao, chiều dài và chiều rộng và những khoảng cách từ lõi thân vách ngăn đến các cấu trúc lân cận khác. Tất cả những trường hợp này được xịt thuốc co mạch 15 phút trước khi tiến hành chụp MRI. Các kết quả thu được sẽ xử lý bằng phần mềm SPSS.

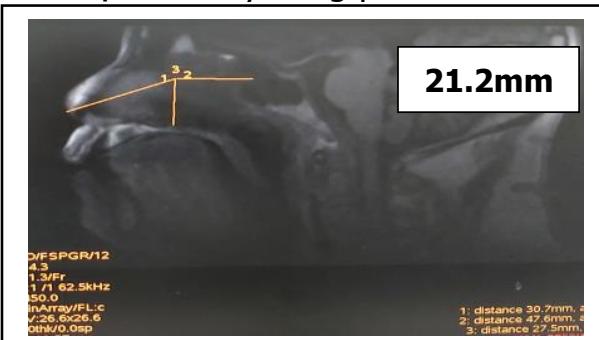

Hình 2. Khoảng cách từ lõi thân vách ngăn đến các điểm mốc

\section{KẾT QUẢ NGHIÊN CỨU}

Tổng số 64 kết quả chup MRI đầu bằng máy Siemens 1.5 tesla được phân tích kết quả xác định các thông số cần đo. Bao gồm 34 nam và 30 nữ, độ tuổi trung bình từ $43.2 \pm 17$ (nhỏ nhất 26, lớn nhất 60). Vùng thân vách ngăn dễ dàng được xác định trên các trường hợp cần khảo sát. Vị trí giúp xác định chính xác cấu trúc thân vách ngăn để thực hiện việc đo là khu vực nằm phía trên đối với phần trước của cuốn mũi dưới và phía trước đầu của cuốn giữa, cấu trúc dạng hình thoi vuốt nhọn dần về phía trước. Cấu trúc này có lõi nằm gần khớp nối của sun vách ngăn và mảnh đứng xương sàng. Chiều rộng trung bình ghi nhận được là $13.1 \mathrm{~mm}$ (SD $2.1 \mathrm{~mm})$, chiều cao là $17.5 \mathrm{~mm}$ (SD $3.4 \mathrm{~mm}$ ). Khoảng cách từ thân vách ngăn đến các mốc giải phẫu khác trong khoang mũi được ghi nhận trong nghiên cứu này như sau: khoảng cách từ lõi đến sàng mũi là $21.2 \mathrm{~mm}(\mathrm{SD} 2.1 \mathrm{~mm})$, đến mặt trước xoang bướm là $36 \mathrm{~mm}$ (SD $3.5 \mathrm{~mm}$ ) và đến chóp mũi là $40.3 \mathrm{~mm}$ (SD $2.9 \mathrm{~mm})$.

\section{BÀN LUÂ̂N}

Nghiên cứu này xác định cấu trúc thân vách ngăn là một thành phần bảo tồn dễ dàng được xác định ở phần trước của vách ngăn. Mặc dù thân vách ngăn tiếp nối liên tục và khó phân biệt với những thành phần lân cận khác của vách ngăn về mặt tổng thể, nhưng cấu trúc này có những khác biệt ranh giới vi thể và những đặc trưng mô học. Điều quan trọng là thân vách ngăn không nên bị nhầm lẫn với lệch vách ngăn hay một thuật ngữ thường được ghi nhận trên nội soi là lệch vách ngăn phần cao.

Các kết quả thu được trong nghiên cứu này có sự khác biệt so với các kết quả nghiên cứu của Costa (2010) trên nhóm người chủng tộc da trắng, sự khác biệt này có thể giải thích là do đặc điểm tháp mũi ở người Việt Nam thuộc chủng tộc da vàng nên có tháp mũi thấp, cánh mũi rộng tác động đến các cấu trúc bên trong khoang mũi. Khi khám mũi qua đèn đội đầu hay nội soi, thân vách ngăn xuất hiện như là phần phù nề của phần trước vách ngăn nằm phía trên khoang mũi, bên trên cuốn mũi dưới, xuất hiện ở cả hai bên khoang mũi. Điều quan trọng là cấu trúc này sẽ thu gọn lại khi dùng thuốc co mạch khác với lệch vách ngăn (không thay đổi khi dùng thuốc co mạch). Trong những năm gần đây nhiều tác giả như Gupta và cộng sự, Haight và Gardiner $[3,4,5,6]$ đã đề cập đến việc can thiệp cấu trúc thân vách ngăn đợn thuần hoặc phối hợp với chỉnh hình vách ngăn, cuốn mũi dưới với mục tiêu cải thiện tình trạng nghẹt mũi. Can thiệp thu nhỏ cấu trúc này có thể thực hiện bằng dao điện, coblator hoặc laser. Tuy nhiển, việc can thiệp này vẫn chưa được chấp nhận và thực hiện một cách phổ biến ở nhiều trung tâm trển thế giới. Khi can thiệp loại bỏ một phần sụn tại khu vực thân vách ngăn giúp cải thiện diện tích cắt ngang của khu vực van mũi trong, nhưng việc này cũng có thể dẫn đến sự thay đổi vi môi 
trường bên trong khoang mũi có thể là cản trở trương lực phó giao cảm từ hoạt động co mạch. Cần nhiều nghiên cứu hơn nữa để đánh giá vai trò của cấu trúc thân vách ngăn trong chức năng sinh lý của mũi và vai trò của nó trong gây ra tình trạng nghẹt mũi, những nghiên cứu tiếp theo có thể hướng đến những tiếp cận điều trị mới.

Hiện nay, tại Việt Nam chưa có nghiên cứu nào khảo sát vai trò của cấu trúc này khi xem xét các nguyên nhân gây nghẹt mũi mạn tính. Bên cạnh đó, chưa có nghiên cứu nào đánh giá việc can thiệp cấu trúc thân vách ngăn để điêu trị nghẹt mũi. Chính vì vậy, trong một số trường hợp bệnh nhân sự cải thiện thông thoáng qua mũi sau phẫu thuật không được như kỳ vọng của bản thân họ trước can thiệp.

\section{KẾT LUÂ̂N}

Cấu trúc thân vách ngăn có dạng hình thoi với kích thước $2-3 \mathrm{~cm}$ nằm phía trước cuốn mũi giữa và phía trên cuốn mũi dưới khoảng $2.5 \mathrm{~cm}$ trên sàng mũi. Kích thước đo được chiều rộng trung bình là $13.1 \mathrm{~mm}$ (SD 2.1mm), chiều cao là $17.5 \mathrm{~mm}$ (SD $3.4 \mathrm{~mm}$ ). Khoảng cách từ thân vách ngăn đến các mốc giải phẫu khác trong khoang mũi được ghi nhận trong nghiên cứu này như sau: khoảng cách từ lõi đên sàng mũi là
$21.2 \mathrm{~mm}(\mathrm{SD} 2.1 \mathrm{~mm})$, đến mặt trước xoang bướm là $36 \mathrm{~mm}(\mathrm{SD} 3.5 \mathrm{~mm}$ ) và đến chóp mũi là $40.3 \mathrm{~mm}$ (SD 2.9mm). Khi đánh giá cấu trúc này cần sử dụng thuốc co mạch xịt vào khoang mũi trước khi tiến soi hay chụp khảo sát hình ảnh học. Cần lưu ý cấu trúc này khi bệnh nhân có than phiền nghẹt mũi mạn tính.

\section{TÀI LIÊU THAM KHẢO}

1. Costa DJ, Sanford T, Janney C, Cooper M, Sindwani R. Radiographic and anatomic characterization of the nasal septal swell body. Arch Otolaryngol Head Neck Surg. 2010;136 (11):1107-10. DOI: 10.1001/archoto.2010.201.

2. Setlur J, Goyal P. Relationship between septal body size and septal deviation. Am J Rhinol Allergy. 2011;25(6):397-400. DOI: 10.2500/ajra.2011.25.3671.

3. Wexler D, Braverman I, Amar M. Histology of the nasal septal swell body (sept alturbinat)

4. Elwany S, Salam SA, Soliman A, Medanni A, Talaat E. The septal body revisited. J Laryngol Otol. 2009;123(3):303-8. DOI: 10.1017/ S0022215108003526. Epub 2008 Sep 17.

5. Bojsen-Moller F, Fahrenkrug J. Nasal swellbodies and cyclic changes in the airpassage of the rat and rabbit nose. J Anat. 1971;110(1):25-37.

6. Murat Cem Miman (2006), "Internal Nasal Valve, Revisited With Objective Facts", Otolaryngology and Head and Neck Surgery 134, pp $41-47$.

\title{
KẾT QUẢ PHẪU THUÂTT TẠO HÌNH CÁC TỔN THƯƠNG GÂN DUỖI Ơं VẾT THƯO'NG BÀN TAY
}

\author{
Phạm Kiến Nhật*, Phạm Thị Việt Dung*, Tạ Thị Hồng Thú*
}

\section{TÓM TẮT}

Mục tiêu nhằm mô tả đặc điểm lâm sàng và đánh giá kểt quả điều trị các tổn thương gân duỗi ở vết thương bàn tay. Nghiên cứu gồm 42 bệnh nhhân với 50 ngón tay tổn thương gân duối bàn tay phẫu thuật tại Bệnh viện Đa khoa Xanh Pôn từ 08/2018 đến $05 / 2021$. Kết quả,tuổi trung bình của bệnh nhân là 38.1; độ tuổi lao động (18-60 tuổi) chiếm 39/42 (92.9\%) bệnh nhân; nam giới chiếm tỷ lệ cao với $37 / 42$ bệnh nhân (88.1\%). Tai nạn lao động là nguyên nhân của $2 / 3$ số ca bệnh. Cơ chế tổn thương cắt do vật sắc nhọn chiếm tỉ lệ $88.1 \%(37 / 42 \mathrm{ca})$. Ngón 2 có tỷ lệ tổn thương cao nhất với 18/50 ngón tổn thương $(36 \%)$, vùng tốn thương hay gặp nhất là vùng VI với 13/50 trường hợp (26\%). Phương pháp khâu nối trực

*Trường Đại học Y Hà Nội

Chịu trách nhiệm chính: Phạm Kiến Nhật

Email: nhatpk.25101995@gmail.com

Ngày nhận bài: 9/8/2021

Ngày phản biện khoa học: 27/8/2021

Ngày duyệt bài: 21/9/.2021 tiếp đước áp dung cho 49/50 trường hợp (98\%) với kỹ thuật khâu thay đổi theo vùng và mức độ tổn thương gân,1 trường hợp vết thương mất đoạn gân được tạo hình bằng ghép gân. Kết quả xa đánh giá theo Miller², kết quả tốt chiếm $38 / 50$ ngón tay $(76 \%)$. Kết luân, đặc điểm lâm sàng của các tổn thương gân duỗi bàn tay rất đa dang, cần có sư phân loai chính xác các loaì vết thương tổn thương gân để đưa ra kỹ thuật phục hồi có hiệu quả. Kỹ thuật khâu nối trực tiếp gân đớn giản, phục hồi gân dưỗi đạt kết quảa cao.

Tư khóa: Vết thương gân duỗi bàn tay, khâu gân, ghép gân.

\section{SUMMARY}

\section{THE PLASTIC SURGERY RESULT OF EXTENSOR TENDON INJURIES IN HAND}

This study aims to describe the clinical characteristics and evaluate the treatment results of extensor tendon injuries in hand. The study was carried out on 42 patients with 50 fingers injured in the extensor tendon of the hand at Saint Paul General Hospital from August 2018 to May 2021. Results: The average age of patients is 38.1 with working age (18- 